\title{
Study of chemical and thermal activations of zeolite-lime blend
}

\author{
M. Meziani ${ }^{1}$, M.Amari ${ }^{2}$, M. Baloul ${ }^{2}, N$. Chelouah $^{1 *}$ \\ ${ }^{1}$ Université de Bejaia, Faculté de Technologie, Laboratoire de Génie de la Construction et d'Architecture, \\ 06000 Bejaia, Algérie \\ ${ }^{2}$ Université de Bejaia, Faculté de Technologie, Département de Génie Civil, 06000 Bejaia, Algérie
}

\begin{abstract}
The advantages of using zeolites are lower costs and better durability, but it requires longer setting time and slower strength development. Chemical and thermal methods have been developed to overcome these disadvantages and to enhance the reactivity of natural zeolite. This paper addressed through a parametric experimental pozzolanic reactivity, the strength and setting time by varying the cure temperature and the amount and type of chemical activators. To this end, several mixtures of natural zeolite-lime pastes were made with two concentrations of chemical activators including $4 \%$ and $8 \%$ of $\mathrm{NaOH}, \mathrm{NaCl}$, and $\mathrm{CaSO}_{4} .2 \mathrm{H}_{2} \mathrm{O}$. The produced pastes were cured at 20,40 , and $80^{\circ} \mathrm{C}$. The blends were also analyzed by X-ray diffraction and infrared spectroscopy. The results showed that curing at high temperatures accelerated the pozzolanic reactivity and increased the compressive strength. The use of $\mathrm{CaSO}_{4} \cdot 2 \mathrm{H}_{2} \mathrm{O}$ led to an increase in the consumption of $\mathrm{Ca}(\mathrm{OH})_{2}$ and strength. Adding $\mathrm{NaCl}$ improved slightly the compressive strength at high curing temperatures. The addition of $8 \% \mathrm{NaOH}$ at $40{ }^{\circ} \mathrm{C}$ significantly improved reactivity and strength. Setting time was accelerated by adding chemical activators to the blends. The raw zeolite had good pozzolanic activity, but the addition of $\mathrm{CaSO}_{4} \cdot 2 \mathrm{H}_{2} \mathrm{O}$ enhanced it.
\end{abstract}

Keywords: zeolite, lime, compressive strength, pozzolanic activity.

\section{INTRODUCTION}

Currently, it is well known that the biggest contributor to greenhouse gas (GHG) emissions is the building sector, responsible for approximately $40-50 \%$ of GHG emissions in the world [1]. Due to its economic contribution, Portland cement is the most used building material. However, it is considered a serious atmospheric pollutant due to the large emission of carbon dioxide during its manufacture. It is estimated that with population growth and industrialization, the pollution generated by the production of cement represents between $5 \%$ and $7 \%$ of carbon dioxide emissions worldwide [2,3]. The only exceptions are blended cements, which contain ingredients other than clinker, which can reduce carbon dioxide emissions by $15 \%$ to $20 \%$. There is currently no other valid and known industrial technology to significantly reduce carbon dioxide emissions from Portland cement. Therefore, researchers and industrials have begun to consider environmental compatibility when selecting construction materials and have been developing strategies to reduce this environmental impact generated by the cement industry [4]. One of these strategies is the substitution of clinker or cement by supplementary cementitious materials (SCMs). Using an available and economical SCM is considered an effective solution. The use of these materials is a very attractive option for reducing the problem of carbon dioxide emissions,

\footnotetext{
*nasser_chelouah@yahoo.fr

Dhttps://orcid.org/0000-0002-6039-8845
}

promoting energy savings, and reducing negative impacts on the environment $[5,6]$.

Among the most common supplementary cementitious materials are pozzolanic materials. Pozzolans associated with lime have provided binders for architectural works and waterproofing plasters for the interior lining of bathrooms, tanks, and aqueducts since ancient times [7]. Nowadays, the use of pozzolanic materials is receiving more and more attention because of their ability to react with calcium hydroxide to form compounds with cementitious properties. Natural zeolites, which are natural pozzolans, combined with lime are one of the oldest building materials $[8,9]$. The zeolites have been used for building since the ancient Roman Empire times in the production of hydraulic cements and concretes. There are many discussions involving the natural zeolites' pozzolanic reactivity in the incorporation of the Portland cement composition. Nowadays, zeolites are innovative materials and a real alternative to classic Portland cement for use in construction [10]. The appropriate use of zeolites enables a lower manufacturing cost with greater durability, however, it requires a longer setting time, and the strength development at the initial age is slower. Several techniques have been developed in the literature to overcome these disadvantages and to enhance the reactivity of natural zeolites. These techniques include mechanical method (prolonged grinding), thermal method (calcination or elevated curing temperature), and chemical method.

The addition of chemicals to pozzolanic materials can increase the pozzolanic reaction rate, strength development rate, and ultimate strength [11]. It is well known that the use of the chemical method as an activator of pozzolanic reactivity has received considerable attention in recent 
years and, on the basis of strength development and cost, the addition of chemical activators is much more effective than prolonged grinding or the elevated curing conditions of lime-pozzolan pastes [12]. Furthermore, the proper chemical activators, the appropriate activator content, and the curing conditions, which can increase the reaction rate of pozzolanic activity and compressive strength, are not well known. So, the objective of the present research is to assess the properties of mordenite-lime cements by conducting a parametric experimental study. This study is interested in finding the optimal curing temperature and the appropriate amount of chemical activators to improve the pozzolanic reactivity of the zeolite, enhance the compressive strength, and regulate the setting time of zeolite-lime blends.

\section{EXPERIMENTAL}

Materials and mix design: the main material used was a mordenite zeolite characterized by a very orderly, stable, and dense structure. It contains chains of five-membered rings of linked silicate and aluminate tetrahedra. This structure forms a three-dimensional architecture with molecular-size channels and cavities promoting cation exchange and the rapid and reversible circulation of water molecules. The material was extracted from natural deposits collected in the Tinebdar area, located in the province of Bejaia, Algeria. It was crushed and ground until a fine powder with a diameter of less than $63 \mu \mathrm{m}$ was obtained. Powder X-ray diffraction (XRD) pattern, infrared spectrum by Fourier transform infrared spectroscopy (FTIR), and a micrograph from scanning electron microscopy (SEM) with a spectrum of energy dispersive X-ray spectroscopy (EDX) of the zeolite are given in Figs. 1a, 2a, and 3, respectively. By using the diffraction patterns available in the PANalytical X'Pert HighScore software database, the XRD pattern of zeolite showed that the material was mainly composed of mordenite with a presence of muscovite and heulandite (Fig. 1a). The infrared spectrum showed vibrations at 3655 and $3408 \mathrm{~cm}^{-1}$ that indicated the presence of $\mathrm{Si}-\mathrm{OH}$ and $\mathrm{OH}$ bonds. A peak at $1638 \mathrm{~cm}^{-1}$ corresponded to the $\mathrm{H}-\mathrm{O}-\mathrm{H}$ vibration, the peaks at 1047 and $430 \mathrm{~cm}^{-1}$ corresponded to the Si-O bond, that at 797 $\mathrm{cm}^{-1}$ corresponded to the $\mathrm{Si}-\mathrm{O}-\mathrm{Al}$ bond, and those at 716 and $519 \mathrm{~cm}^{-1}$ corresponded to the $\mathrm{Al}-\mathrm{O}$ bond. All the connections previously reported corresponded to zeolite (Fig. 2a). The particle morphology showed the presence of irregular and angled particles with a diameter of up to about $63 \mu \mathrm{m}$ (Fig. 3a). The chemical composition of the zeolite determined by EDX analysis indicated the presence of significant contents of $\mathrm{Si}$ and $\mathrm{Al}$ (Fig. 3b). Hydrated lime $\left[\mathrm{Ca}(\mathrm{OH})_{2}\right]$ was obtained after a complete reaction of quicklime with water. XRD pattern of hydrated lime and its FTIR spectrum are shown in Figs. 1b and $2 \mathrm{~b}$, respectively. The $\mathrm{O}-\mathrm{H}$ and $\mathrm{C}-\mathrm{H}$ bonds indicated the presence of portlandite; the $\mathrm{C}=\mathrm{C}$ bonds indicated the presence of calcite.

The test specimens were zeolite-lime pastes whose proportions of the two components were equal. The amount of mixing water was taken on the basis of the quantity
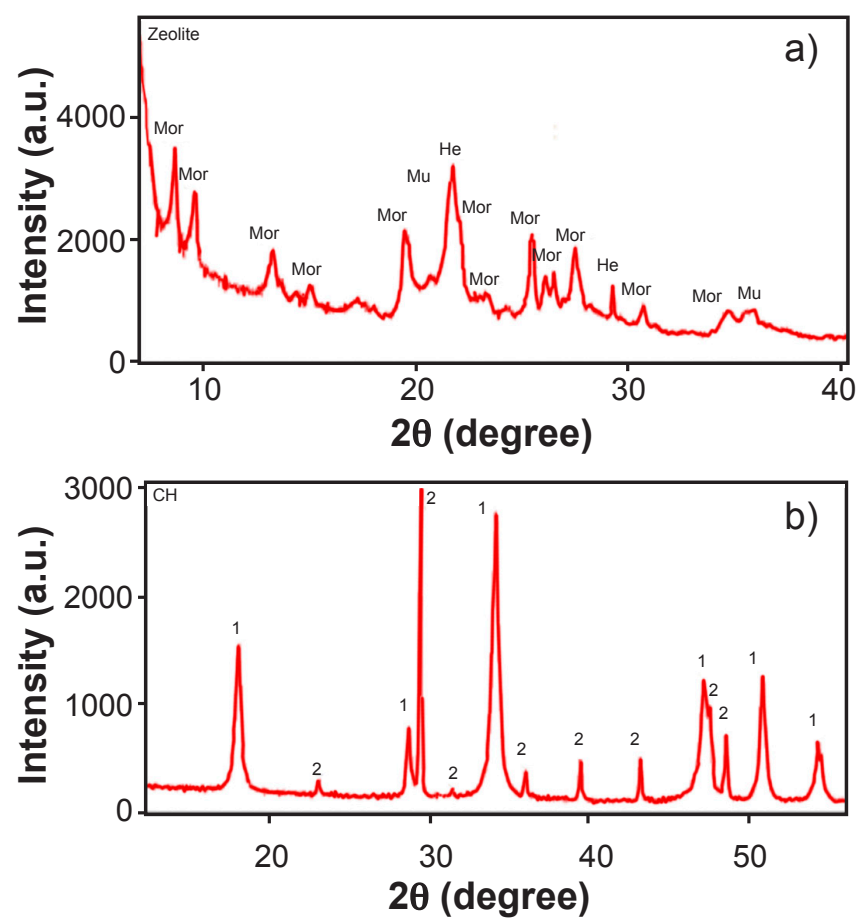

Figure 1: XRD patterns of: a) zeolite (Mor: mordenite; $\mathrm{Mu}$ : muscovite; He: heulandite); and b) hydrated lime, $\mathrm{Ca}(\mathrm{OH})_{2}(1$ : portlandite; 2 : calcite).
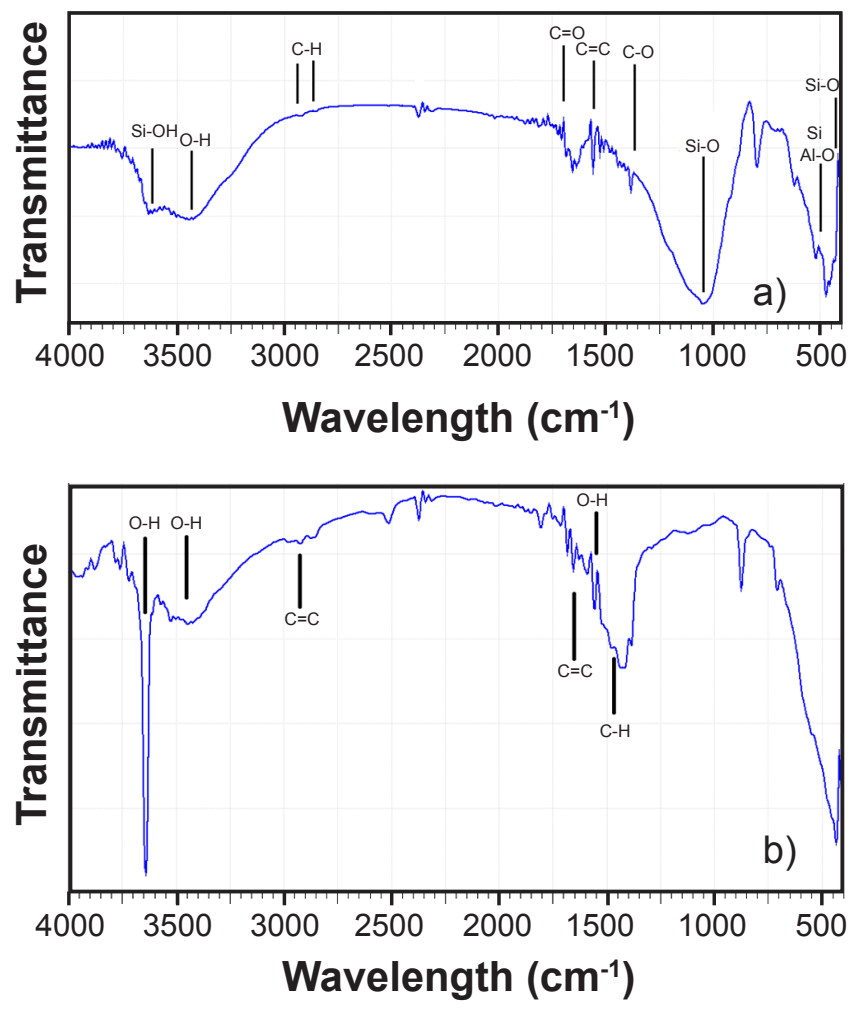

Figure 2: FTIR spectra of: a) zeolite; and b) hydrated lime, $\mathrm{Ca}(\mathrm{OH})_{2}$.

required to provide a standard consistency to the mixture. The latter was obtained at a water/binder ratio of 0.63 . In order to optimize the pozzolanic reactivity of the zeolite, the chemical 

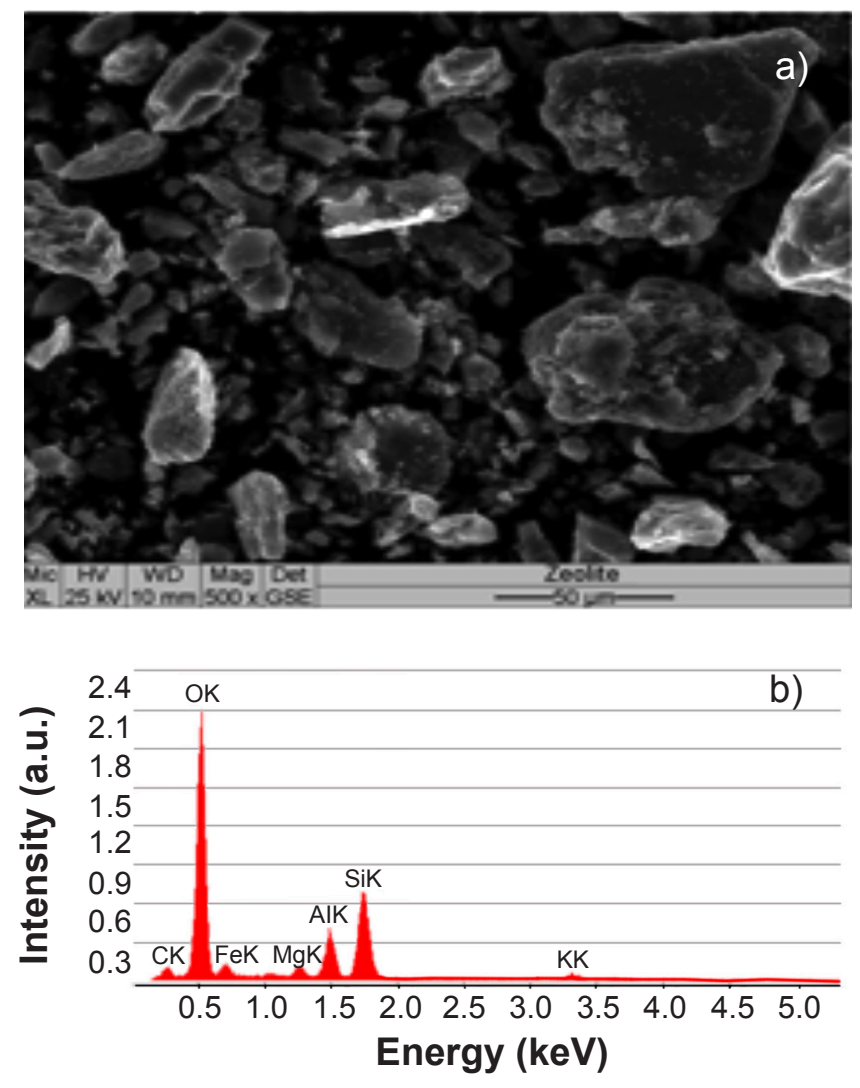

Figure 3: SEM micrograph (a) and EDX spectrum (b) of the zeolite.

reagents $\mathrm{NaOH}, \mathrm{CaSO}_{4} \cdot 2 \mathrm{H}_{2} \mathrm{O}$, and $\mathrm{NaCl}$ were incorporated into the lime-zeolite blends. The dosages of the chemical activators were $4 \%$ and $8 \%$ based on the mass of mixing water. The reagent grades of $\mathrm{NaOH}$ or $\mathrm{NaCl}$ were added with stirring to demineralized water. As for $\mathrm{CaSO}_{4} \cdot 2 \mathrm{H}_{2} \mathrm{O}$, it was added directly as a powder in the zeolite-lime blend. After preparation and mixing, the pastes were stored in $50 \times 50 \times 50 \mathrm{~mm}^{3}$ prismatic molds wrapped in a double layer of cling film to minimize exposure to carbon dioxide and water loss through evaporation and were cured in a temperaturecontrolled chamber for $48 \mathrm{~h}$. After removal from the mold, they were wrapped again in cling film and kept in controlled atmospheres at 20,40 , and $80{ }^{\circ} \mathrm{C}$ for 28 days.

Experimental investigations: tests of the setting time of the zeolite-lime blend were carried out according to NF EN 196-3 standard [13], which describes the testing method used to determine the setting time of hydraulic cement by a Vicat needle. The test made it possible to follow the evolution of the stiffening of a zeolite-lime blend with a normal consistency by using a manual Vicat device. The purpose of this test was to highlight the evolution of the stiffening of the zeolite-lime paste under different thermal and chemical conditions. The initial and final setting times were measured by increasing the rate of the activators $\left(\mathrm{NaOH}, \mathrm{CaSO}_{4} \cdot 2 \mathrm{H}_{2} \mathrm{O}\right.$, and $\left.\mathrm{NaCl}\right)$ from $4 \%$ to $8 \%$. To identify the relationship between hardening and temperature, the initial and final setting times of the zeolite-lime blend were measured for curing at 20 , 40 , and $80^{\circ} \mathrm{C}$. The compressive strength of the zeolite-lime blend was measured according to NF EN 196-1 standard
[14]. The test was performed on $50 \times 50 \times 50 \mathrm{~mm}^{3}$ cubic test pieces for each type $\left(\mathrm{NaOH}, \mathrm{CaSO}_{4} \cdot 2 \mathrm{H}_{2} \mathrm{O}\right.$, and $\left.\mathrm{NaCl}\right)$ and rate $(4 \%$ and $8 \%$ ) of activators. To assess the differences in the strength caused by temperature changes, compressive strength tests were conducted on samples hardened at 20, 40 , and $80{ }^{\circ} \mathrm{C}$ during 28 days.

In order to evaluate the pozzolanic activity of the zeolite (mordenite) and the effect of chemical activators in improving this activity, the Chapelle test was used. $1 \mathrm{~g}$ of zeolite was added in $200 \mathrm{~mL}$ of distilled water followed by the addition of $1 \mathrm{~g}$ of $\mathrm{Ca}(\mathrm{OH})_{2} .4 \%$ or $8 \%$, by mass of distilled water, of chemical activators $\left(\mathrm{CaSO}_{4} \cdot 2 \mathrm{H}_{2} \mathrm{O}\right.$ or $\mathrm{NaCl}$ ) were added to the mixtures. Those were then boiled for $16 \mathrm{~h}$. After that, the solution was filtrated then titrated with $\mathrm{HCl}$ solution $(1 \mathrm{~N})$ and phenolphthalein in order to find the amount of $\mathrm{Ca}(\mathrm{OH})_{2}$ that did not participate in the pozzolanic reaction. The amount of $\mathrm{Ca}(\mathrm{OH})_{2}$ unreacted with the zeolite in the presence of $\mathrm{NaOH}$ was not measured because the results obtained by the Chapelle test were not reliable. In order to investigate the extent of development of chemical activation of the zeolite, the hardened zeolitelime pastes were ground and analyzed by Fourier transform infrared spectrometry (FTIR) in transmission mode using a spectrometer (Cary 630 FTIR, Agilent Technol.). To determine the mineralogical composition of the zeolite-lime blends, few grams of the ground sample were taken and analyzed by X-ray diffraction (XRD). The test was recorded between $2 \theta$ values ranging from $5^{\circ}$ to $50^{\circ}$ with a scanning speed of $1 \%$ min using an X-ray diffractometer (Expert Pro, Panalytical) and Ni-filtered CuK $\alpha$ radiation $(\lambda=1.54056$ $\AA)$. Continuous scan type was used for the analysis of the samples. The X-ray diffractograms were recorded for the control blend and blends with the highest compressive strengths.

\section{RESULTS AND DISCUSSION}

Setting time: the setting times of zeolite-lime pastes containing different rates of chemical activators and stored under different thermal conditions are given in Table I. It was seen that all the measured setting times were acceptable compared to standard values given for Portland cement by NF EN 197-1 standard [15]. When the control paste was hardened at $20^{\circ} \mathrm{C}$, the initial setting time value was over 30 $\mathrm{h}$ while the final setting time was not observed. The setting times were dramatically reduced when hardened at 40 and $80{ }^{\circ} \mathrm{C}$. Nevertheless, when hardened at 40 and $80{ }^{\circ} \mathrm{C}$, the initial setting time has greatly decreased by around 26 and $28 \mathrm{~h}$, respectively. The final setting time was remarkably decreased by increasing the curing temperature to $40{ }^{\circ} \mathrm{C}$ where only $96 \mathrm{~min}$ was recorded between the start and the end of the setting; at $80{ }^{\circ} \mathrm{C}$ this time was reduced to 57 min. This offered a setting time saving of $55 \%$ following the change from 40 to $80{ }^{\circ} \mathrm{C}$. The hardening at elevated temperatures resulted in significant differences in the setting times [16]. In comparison with control paste stored at 20 ${ }^{\circ} \mathrm{C}$, the addition of chemical activators was essential for 
Table I - Setting time of zeolite-lime pastes with different activator rates and curing temperatures.

\begin{tabular}{|c|c|c|c|c|c|c|c|}
\hline \multirow{2}{*}{ Sample } & \multirow{2}{*}{$\begin{array}{c}\text { Activator } \\
\text { rate }(\%)\end{array}$} & \multicolumn{3}{|c|}{ Initial setting time (h) } & \multicolumn{3}{|c|}{ Final setting time (h) } \\
\hline & & $20^{\circ} \mathrm{C}$ & $40^{\circ} \mathrm{C}$ & $80^{\circ} \mathrm{C}$ & $20^{\circ} \mathrm{C}$ & $40^{\circ} \mathrm{C}$ & $80^{\circ} \mathrm{C}$ \\
\hline Control & 0 & 32.00 & 5.67 & 2.80 & N-obs. & 7.25 & 3.75 \\
\hline \multirow{2}{*}{$\mathrm{NaOH}$} & 4 & 12.00 & 1.95 & 1.17 & 26.50 & 4.12 & 1.42 \\
\hline & 8 & 5.50 & 1.67 & 0.83 & 18.00 & 3.42 & 0.91 \\
\hline \multirow{2}{*}{$\mathrm{NaCl}$} & 4 & 29.00 & 4.50 & 2.67 & 48.50 & 6.00 & 3.34 \\
\hline & 8 & 21.00 & 3.00 & 1.75 & 40.17 & 3.50 & 2.00 \\
\hline \multirow{2}{*}{$\mathrm{CaSO}_{4} \cdot 2 \mathrm{H}_{2} \mathrm{O}$} & 4 & 19.00 & 4.00 & 2.50 & 28.00 & 9.00 & 3.29 \\
\hline & 8 & 13.00 & 2.25 & 1.59 & 20.00 & 7.00 & 2.16 \\
\hline
\end{tabular}

the improvement of the setting of the zeolite-lime paste. $\mathrm{NaOH}$ was the most effective activator. Indeed, its presence in the mixture was very suitable for regulating the setting time. In addition, increasing the $\mathrm{NaOH}$ amount from $4 \%$ to $8 \%$ accelerated the initial and final setting time by $6.5 \mathrm{~h}$ and $28 \mathrm{~min}$, respectively. In previous research, it was found that when the $\mathrm{NaOH}$ concentration values of the mixes increase, the setting time values of the mixes decrease [17]. $\mathrm{CaSO}_{4} \cdot 2 \mathrm{H}_{2} \mathrm{O}$ was a good contributor to improving setting time. Its incorporation greatly reduced the setting times. In fact, increasing its amount from $4 \%$ to $8 \%$ accelerated the initial and final setting times by 6 and $1.5 \mathrm{~h}$, respectively. The efficiency of $\mathrm{NaCl}$ was visibly reduced compared to the two activators. Due to the times given for the initial and final setting, chemical activation by $\mathrm{NaCl}$ at room temperature $\left(20^{\circ} \mathrm{C}\right)$ is not recommended.

The setting times measured at room temperature can be influenced by the nature of the chemical activator and its proportion in the paste. However, these times remain remarkably delayed. The time of setting could be considered as an indication for the kinetics of hydration reactions so that a relatively long setting time shows that the reactions proceed very slowly at room temperature [18]. Thereupon, an evaluation of the setting times was made under different temperature conditions. Indeed, the three chemical activators contributed favorably to overall temperatures by reducing setting times. By using sodium hydroxide reagent, the initial setting time went down from 330 to $100 \mathrm{~min}$ then to $49 \mathrm{~min}$ following the increase in temperature from 20 to $40{ }^{\circ} \mathrm{C}$ then to $80^{\circ} \mathrm{C}$, respectively. This gave a time saving of $230 \mathrm{~min}$ at $40{ }^{\circ} \mathrm{C}$ and $281 \mathrm{~min}$ at $80{ }^{\circ} \mathrm{C}$. The incorporation of calcium sulfate dihydrate in mixtures stored at different temperatures considerably regulated the setting times. In fact, the initial setting time went down from $780 \mathrm{~min}$ at $20^{\circ} \mathrm{C}$ to $135 \mathrm{~min}$ at $40{ }^{\circ} \mathrm{C}$ then to $95 \mathrm{~min}$ at $80^{\circ} \mathrm{C}$. This offered time savings of 645 and $685 \mathrm{~min}$ at 40 and $80{ }^{\circ} \mathrm{C}$, respectively. Regarding sodium chloride reagent, unlike its behavior at room temperature, it was identified as a chemical activator with a massive influence on the setting time measured at elevated temperatures. The initial setting time of $1260 \mathrm{~min}$ measured at $20{ }^{\circ} \mathrm{C}$ was reduced to $180 \mathrm{~min}$ at $40{ }^{\circ} \mathrm{C}$ and then to only $105 \mathrm{~min}$ at $80{ }^{\circ} \mathrm{C}$. The lower initial setting times at higher activator concentrations indicated enhanced reactivity of the pozzolan [19]. This observation did not exclude the final setting time, which was also reduced with the increase in the amount of chemical activators and the curing temperature.

FTIR analysis: FTIR spectra of hardened zeolite-lime pastes at 28 days under different curing temperatures and chemical activation conditions are shown in Fig. 4. By comparing the FTIR spectra of the control paste stored at different temperatures (Fig. 4), it was seen that the vibratory behavior of the spectrum of the control paste at $80{ }^{\circ} \mathrm{C}$ was typically the same as that of the same sample at $20^{\circ} \mathrm{C}$. Moreover, these spectra showed the presence of calcium hydroxide $\left[\mathrm{Ca}(\mathrm{OH})_{2}\right]$ marked by the stretching vibration of $\mathrm{O}-\mathrm{H}$ at $3640 \mathrm{~cm}^{-1}$ [20]. A triplet at 1420, 876, and $712 \mathrm{~cm}^{-1}$ that characterizes the vibrations of elongation of the $\mathrm{C}-\mathrm{O}$ bond was accompanied by harmonics at 2975, 2875, 2515, and $1772 \mathrm{~cm}^{-1}$ ascribable to carbonates $\left(\mathrm{CaCO}_{3}\right)$ due to the natural carbonation of the binder during mixing (carbonation of portlandite). The spectra showed also characteristic peaks of calcium silicate hydrates (CSH) at 965 and $961 \mathrm{~cm}^{-1}$ marked by the Si-O vibration [21]. The difference between the two spectra recorded at 20 and $80{ }^{\circ} \mathrm{C}$ with that recorded at $40{ }^{\circ} \mathrm{C}$ was the decrease in the peak intensity at $3640 \mathrm{~cm}^{-1}$ and the increase in the band at $1636 \mathrm{~cm}^{-1}$ marked by the $\mathrm{H}-\mathrm{O}-\mathrm{H}$ bending vibrations of molecular water; this confirmed the consumption of $\mathrm{Ca}(\mathrm{OH})_{2}$ and the enhancement of pozzolanic activity [22]. Changes in the amount of activators did not result in differences in the spectra of the pastes stored at $20{ }^{\circ} \mathrm{C}$ (Fig. 4a). These spectra differed from the control spectrum by the presence of the band at $3369 \mathrm{~cm}^{-1}$ that characterizes the appearance of the water ascribable to the hydrates. From Fig. $4 \mathrm{~b}$, the band at $3362 \mathrm{~cm}^{-1}$ ascribable to the appearance of the constitutive water did not appear on the control, $4 \%$ $\mathrm{NaOH}$, and $8 \% \mathrm{NaOH}$ spectra. In Fig. $4 \mathrm{c}$, it can be seen that all of the spectra were identical to that of the control paste stored at 80 and $20{ }^{\circ} \mathrm{C}$. In general, the FTIR makes it possible to establish a physicochemical analysis of the zeolite as well as its pozzolanic reactivity during its reaction with lime, whether under chemical or thermal activation.

Pozzolanic reactivity: according to the Chapelle test results showed in Table II, $0.891 \mathrm{~g}$ of $\mathrm{Ca}(\mathrm{OH})_{2}$, were consumed per gram of zeolite. This fact indicated a good pozzolanic activity of the zeolite. This result was confirmed by the FTIR spectrum of lime-zeolite control paste (Fig. 4). 
The decrease of the vibration intensity at $3640 \mathrm{~cm}^{-1}$ and the increase of intensity at $1636 \mathrm{~cm}^{-1}$ indicated the consumption of $\mathrm{Ca}(\mathrm{OH})_{2}$ and the formation of calcium silicate hydrates. Table II presents the $\mathrm{Ca}(\mathrm{OH})_{2}$ content in relation to the activator addition at different contents. There was a decrease of the $\mathrm{Ca}(\mathrm{OH})_{2}$ content in the sample incorporating $4 \%$ and $8 \% \mathrm{CaSO}_{4} .2 \mathrm{H}_{2} \mathrm{O}$. This remark was confirmed by the presence of the band at $3369 \mathrm{~cm}^{-1}$ (Fig. 4) which characterized the appearance of the water ascribable to the hydrates. However, adding $\mathrm{NaCl}$ to the lime-zeolite mixture did not improve the consumption of $\mathrm{Ca}(\mathrm{OH})_{2}$. Adding $\mathrm{NaCl}$ showed either no effect or negative effect on increasing compressive strength. The most likely contributor to this effect was the decreased solubility of $\mathrm{Ca}(\mathrm{OH})_{2}$ [23]. The addition of chlorides decreases the solubility of $\mathrm{Ca}(\mathrm{OH})_{2}$ but increases its dissolution rate significantly. It is the dissolution rate,
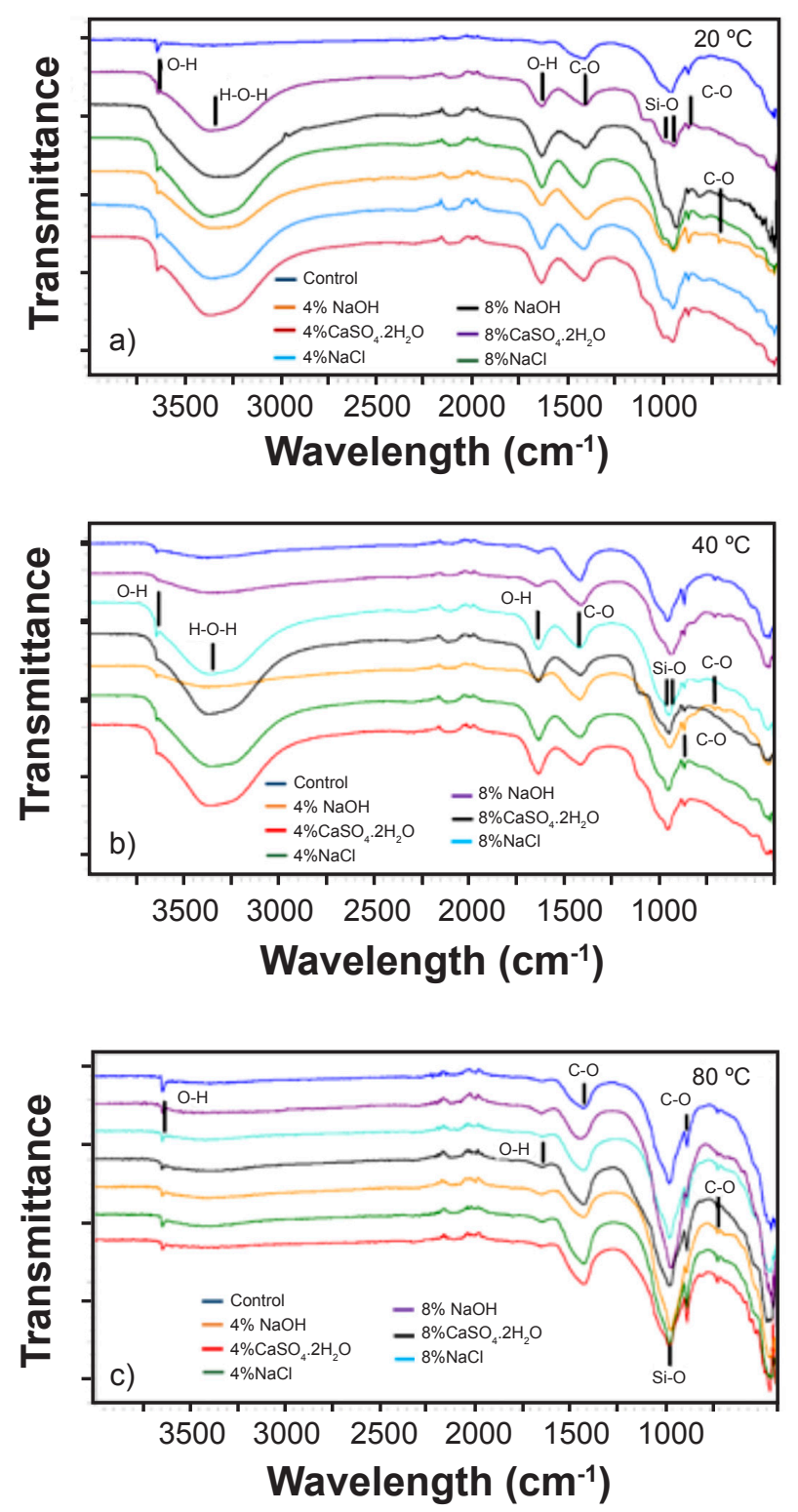

Figure 4: FTIR spectra of zeolite-lime pastes stored at: a) $20{ }^{\circ} \mathrm{C}$; b) $40{ }^{\circ} \mathrm{C}$; and c) $80^{\circ} \mathrm{C}$. rather than the solubility, that affects the rate of pozzolanic reaction in the lime-pozzolan pastes [24]. When a limezeolite blend is mixed with water, $\mathrm{Ca}(\mathrm{OH})_{2}$ in the blend hydrolyses and the solution reaches a high $\mathrm{pH}$ value very quickly. In a high $\mathrm{pH}$ solution, the $\mathrm{OH}$ - attack the silicate or aluminosilicate, so the network of the pozzolanic materials is broken and depolymerized species enter the solution. When $\mathrm{Ca}^{2+}$ ions contact the dissolved monosilicates and aluminate species, calcium silicate and aluminate hydrates (similar to those formed in hydrated cement) are formed. Therefore, these compounds contribute to the mechanical strength of the material [25].

Table II - $\mathrm{Ca}(\mathrm{OH})_{2}$ content measured by using the Chapelle test.

\begin{tabular}{ccc}
\hline Sample & $\begin{array}{c}\text { Activator } \\
\text { rate }(\%)\end{array}$ & $\begin{array}{c}\text { Mass }(\mathrm{g}) \text { of } \mathrm{Ca}(\mathrm{OH})_{2} \\
\text { consumed per g of zeolite }\end{array}$ \\
\hline Control & 0 & 0.891 \\
\multirow{2}{*}{$\mathrm{NaCl}$} & 4 & 0.885 \\
& 8 & 0.896 \\
$\mathrm{CaSO}_{4} \cdot 2 \mathrm{H}_{2} \mathrm{O}$ & 4 & 0.971 \\
& 8 & 0.981 \\
\hline
\end{tabular}

Compressive strength: the results of the compressive strength test of zeolite-lime pastes in relation to the different chemical activators and thermal conditions are given in Fig. 5. The results showed changes in compressive strength relative to curing temperatures of the zeolite-lime pastes. Test pieces hardened at $40{ }^{\circ} \mathrm{C}$ had the highest compressive strength. Test pieces hardened at $80{ }^{\circ} \mathrm{C}$ did not show significant improvement in compressive strength relative to those hardened at $20{ }^{\circ} \mathrm{C}$. In addition, the temperature of $80{ }^{\circ} \mathrm{C}$ reduced compressive strength by approximately $36 \%$ compared to $40{ }^{\circ} \mathrm{C}$. So, the optimal curing temperature was $40^{\circ} \mathrm{C}$. It seems that temperature had a very significant effect on the strength development of the zeolite-lime paste. This may be attributed to the high hydration activation energy [11]. At higher temperatures, a detrimental effect was observed as evidenced by decreasing the compressive strength [26]. It is possible that the lack of precuring at ambient conditions hampered obtaining a higher compressive strength at a temperature higher than $40{ }^{\circ} \mathrm{C}$ [27]. Compressive strength intensified as the amount of chemical activator increased. A higher concentration of the activator improved the dissolution of the aluminosilicate and, therefore, improving the mechanical properties $[17,28-30]$. Indeed, the highest compressive strength was obtained by increasing the amount of chemical reagents from $4 \%$ to $8 \%$ in the zeolite-lime paste. Comparing to the control paste, those containing $8 \%$ of $\mathrm{CaSO}_{4} \cdot 2 \mathrm{H}_{2} \mathrm{O}, \mathrm{NaCl}$, and $\mathrm{NaOH}$ improved compressive strength by $8 \%, 18 \%$, and $25 \%$ respectively.

The optimal activator-temperature couple for greater compressive strength was $8 \%-80{ }^{\circ} \mathrm{C}$ in the case of $\mathrm{CaSO}_{4} \cdot 2 \mathrm{H}_{2} \mathrm{O}$ and $\mathrm{NaCl}$ and $8 \%-40{ }^{\circ} \mathrm{C}$ in the case of $\mathrm{NaOH}$. The paste containing $8 \% \mathrm{CaSO}_{4} \cdot 2 \mathrm{H}_{2} \mathrm{O}$ at $80{ }^{\circ} \mathrm{C}$ possessed a 


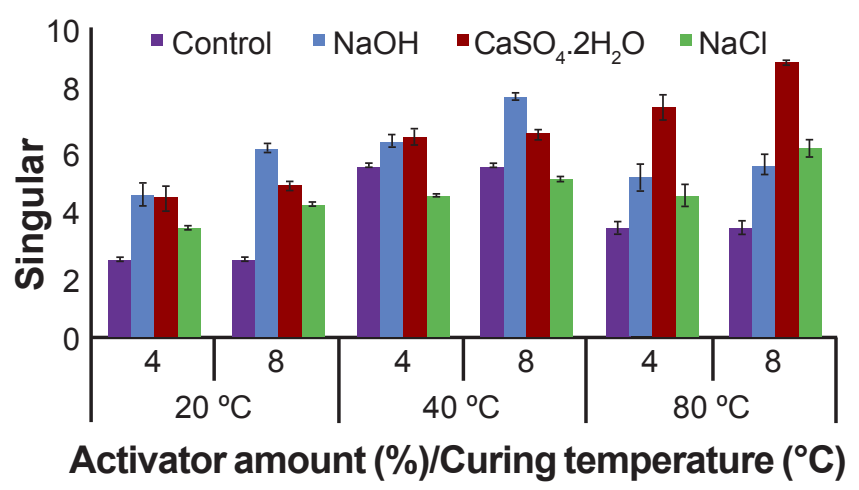

Figure 5: Compressive strength of zeolite-lime pastes depending on chemical activation.

compressive strength of $8.87 \mathrm{MPa}$, which offered a strength gain of $72 \%$ compared to the control paste stored at the same temperature. This value argued for the effectiveness of this activator in improving the strength of zeolite-lime paste stored at elevated temperatures. In large volume concrete applications, it can be expected that internal temperatures will rise well above ambient; the presence of sulfate activator in such an environment is likely to have an appreciable effect on the rate of activation of pozzolan, and thus on the rate of compressive strength development [31,32]. The high strength of the sulfate ions activated pastes is attributed to the acceleration of pozzolanic reaction and the formation of ettringite, which densifies the structure of hardened limepozzolan pastes significantly [24]. Incorporating $8 \%$ of $\mathrm{NaCl}$ into the zeolite-lime paste stored at $80^{\circ} \mathrm{C}$ gave a maximum strength of $6.10 \mathrm{MPa}$ thus contributing to the increase in strength by a profit of $59 \%$ compared to the control paste. The addition of $\mathrm{NaCl}$ to the pozzolan lime blends resulted in a significant increase in strength gain when compared to specimens without $\mathrm{NaCl}$, which demand longer curing periods to reach similar strength values [33, 34]. The addition of $8 \% \mathrm{NaOH}$ to the zeolite-lime paste stored at 40 ${ }^{\circ} \mathrm{C}$ seemed to achieve a fairly high compressive strength (7.75 MPa), with a profit of $68 \%$ compared to the control paste. In the case of $\mathrm{NaOH}$, when the curing temperature raised, the compressive strength improved as well, but only up to $40^{\circ} \mathrm{C}$ [35]. A previous study has indicated that a longer time or higher temperature is required for a pozzolan-based geopolymer paste sample with a higher concentration of alkaline solution beyond $7.5 \mathrm{M}$ concentration to improve the mechanical properties [28].

$X$-ray diffraction analysis: X-ray diffractometry was used for investigating a number of cured specimens, those that gave the highest compressive strengths. The obtained patterns presented in Fig. 6 however were quite the same showing a presence of: i) calcium silicate hydrate (CSH) derived from the pozzolanic reaction between the zeolite and calcium hydroxide; ii) zeolite (mordenite) and portlandite that did not fully react; iii) calcite in weak intensities, while its presence increased in samples containing $\mathrm{CaSO}_{4} .2 \mathrm{H}_{2} \mathrm{O}$; it was produced by the reaction of lime with $\mathrm{CO}_{2}$ during the mixing period (carbonation of lime); and iv) ettringite in the

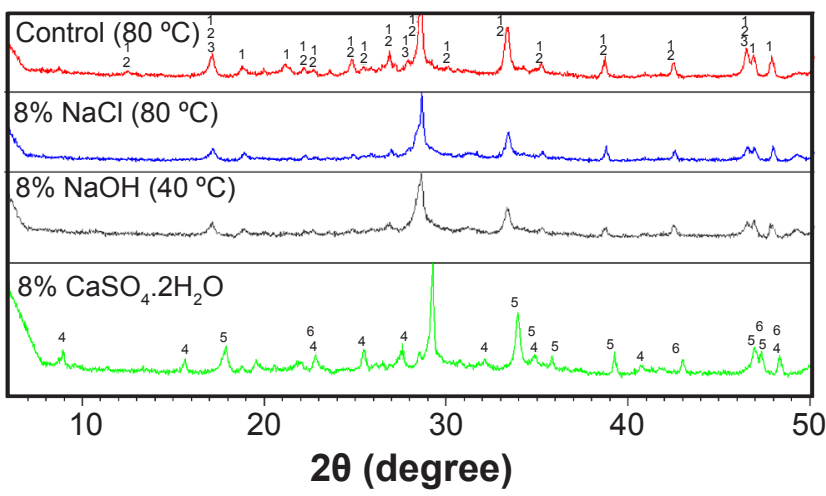

Figure 6: XRD patterns of zeolite-lime blends that gave the highest compressive strengths (1: mordenite; 2 : $\mathrm{CSH} ; 3$ : portlandite; 4: ettringite; 5: gypsum; 6: calcite).

$\mathrm{X}$-ray diffractograms of samples containing $\mathrm{CaSO}_{4} \cdot 2 \mathrm{H}_{2} \mathrm{O}$; this ettringite was formed after hardening of the zeolitelime paste, not having noticed any swelling or cracks visible to the naked eye on the surface of the samples; its effect was therefore beneficial; indeed, its presence increased the compressive strength (Fig. 5); in a previous study, it was observed that the peak intensities of ettringite in the pastes increased with the dosage of chemical activator; at the same time, the strength increased with dosage of chemical activator; it is postulated that a significant increase in ettringite content due to activator dosage has a key influence on the observed compressive strength [31]; ettringite is known as a strength enhancing material by filling pores [23].

\section{CONCLUSIONS}

Based on the findings of this research, the following conclusions can be drawn: i) the increase of the amount of chemical activator and curing temperature resulted in a decrease in setting times; ii) curing at high temperature improved the reactivity of the zeolite by increasing the compressive strength; iii) the use of $\mathrm{CaSO}_{4} \cdot 2 \mathrm{H}_{2} \mathrm{O}$ as a chemical activator led to increasing the consumption of $\mathrm{Ca}(\mathrm{OH})_{2}$ and compressive strength, which increased as the content of activator increased; iv) $\mathrm{NaCl}$ contributed slightly to the increase in compressive strength at high curing temperatures; it is therefore presented entirely as an effective and at the same time inexpensive activator; v) the compressive strength results obtained by adding $\mathrm{NaOH}$ were considered important; the optimum percentage of $\mathrm{NaOH}$ was $8 \%$ at $40{ }^{\circ} \mathrm{C}$; on the other hand when a higher amount of $\mathrm{NaOH}$ was applied, liquefaction occurred and it was difficult to produce test pieces.

\section{REFERENCES}

[1] M.M. Khasreen, P.F.G. Banfill, G.F. Menzies, Sustainability 1 (2009) 674.

[2] N.D. Lagaros, Struct. Multidiscip. Optim. 58 (2018) 1751 .

[3] L.G. Li, A.K.H. Kwan, Cem. Concr. Compos. 60 (2015) 
17.

[4] P.C.R.A. Abrão, F.A. Cardoso, V.M. John, Cerâmica 65, Suppl. 1 (2019) 75.

[5] T. Hanein, J. Galvez-Martos, M.N. Bannerman, J. Clean. Prod. 172 (2018) 2278.

[6] K.-H. Yang, J.-K. Song, K.-I. Song, J. Clean. Prod. 39 (2013) 265.

[7] F. Massazza, Cem. Concr. Compos. 15 (1993) 185.

[8] G. Boffey, E. Hirst, J. Archit. Conserv. 3 (1999) 34.

[9] H.T. Ozkahraman, A. Bolatturk, Constr. Build. Mater. 20 (2006) 435.

[10] M.S. Picanço, R.S. Angélica, M.S. Barata, Cerâmica 57, 344 (2011) 467.

[11] C. Shi, R.L. Day, Cem. Concr. Res. 31 (2001) 813.

[12] C. Shi, R.L. Day, Cem. Concr. Res. 30 (2000) 51.

[13] NF EN 196-3, "Methods of testing cement, part 3: determination of setting time and soundness", Eur. Comm. Stand., Brussels (2017).

[14] NF EN 196-1, "Methods of testing cement, part 1: determination of strength", Eur. Comm. Stand., Brussels (2016).

[15] NF EN 197-1, "Cement, part 1: composition, specifications and conformity criteria for common cements", Eur. Comm. Stand., Brussels (2001).

[16] B. Jo, J. Choi, K. Yoon, J. Park, Constr. Build. Mater. 36 (2012) 1059.

[17] I. Tekin, Constr. Build. Mater. 127 (2016) 607.

[18] A. Allahverdi, K. Mehrpour, E.N. Kani, Ceram.-Silikaty 52 (2008) 16.

[19] J. Sarfo-Ansah, E. Atiemo, K.A. Boakye, Mater. Sci. Appl. 5 (2014) 86.
[20] Z. Liang, Q. Wang, B. Dong, B. Jiang, F. Xing, RSC Adv. 8 (2018) 39536.

[21] F. Farcas, P. Touzé, Bull. Des Lab. Des Ponts Chaussées 230 (2001) 77.

[22] B. Lothenbach, D. Nied, E. L'Hôpital, G. Achiedo, A. Dauzères, Cem. Concr. Res. 77 (2015) 60.

[23] S. Sim, H. Lee, D. Jeon, H. Song, W.S. Yum, D. Kim, J. Suh, J.E. Oh, Appl. Sci. 8 (2018) 2.

[24] C. Shi, R.L. Day, Cem. Concr. Res. 30 (2000) 607.

[25] T. Perraki, G. Kakali, F. Kontoleon, Microporous Mesoporous Mater. 61 (2003) 205.

[26] P. Rovnaník, Constr. Build. Mater. 24 (2010) 1176.

[27] E. Najafi, K.Æ. Ali, J. Mater. Sci. 44 (2009) 3088.

[28] D. Bondar, C.J. Lynsdale, N.B. Milestone, N. Hassani, A.A. Ramezanianpour, Cem. Concr. Compos. 33 (2011) 251.

[29] N. Ghafoori, M. Najimi, B. Radke, Environ. Earth Sci. 75 (2016) 1110.

[30] H. Takeda, S. Hashimoto, H. Kanie, S. Honda, Y. Iwamoto, Ceram. Int. 40 (2014) 4071.

[31] C. Shi, R.L. Day, Cem. Concr. Res. 25 (1995) 15.

[32] M.A. Nawaz, A. Babar, L.A. Qureshi, H.M. Usman Aslam, H. Iqrar, B. Masood, S.S. Raza, Case Stud. Constr. Mater. 13 (2020) e00407.

[33] N.C. Consoli, R.B. Saldanha, H. Carlos, S. Filho, Can. Geotech. J. 56 (2019) 1.

[34] A. Polettini, R. Pomi, E. Fortuna, J. Hazard. Mater. 162 (2009) 1292.

[35] H. Baykara, M.H. Cornejo, R. Murillo, A. Gavilanes, C. Paredes, J. Elsen, Mater. Struct. 50 (2017) 1.

(Rec.05/01/2021, Rev. 28/05/2021, Ac. 02/06/2021) 